\title{
ESTIMATION OF STATIC COULOMB STRESS CHANGE AND STRONG MOTION SIMULATION FOR JIUZHAIGOU 7.0 EARTHQUAKE BASE ON SENTINEL-1 INSAR DATA INVERSION
}

\author{
W. H. Shen*, Y. Luo, Q.S. Jiao \\ Key Laboratory of Crustal Dynamics, Institute of Crustal Dynamics, China Earthquake Administration, Beijing, China - \\ shenxiaoxi200212@163.com
}

WG III/3

KEY WORDS: InSAR, Coulomb Stress Change, Slip Inversion, Strong Motion, Aftershocks, Slip Model, Jiuzhaigou Earthquake

\begin{abstract}
:
On August 8, 2017, an earthquake of M 7.0 occurred at Jiuzhaigou. Based on the Sentinel-1 satellite InSAR data, we obtained coseismic deformation field and inverted the source slip model. Results show that this event is dominated by strike slip, and the total released seismic moment is $8.06 \times 10^{18} \mathrm{~N} \cdot \mathrm{m}$, equivalent to an earthquake of $M_{\mathrm{w}} \sim 6.57$. We calculated static stress changes along strike and dip direction, and the static stress analysis show that the average stress drop are at low level, which may be responsible for the low level of ground motion during Jiuzhaigou earthquake. The coseismic Coulomb stress changes are calculated base on the inverted slip model, which revealed that $82.59 \%$ of aftershocks are located in the Coulomb stress increasing area, $78.42 \%$ of total aftershocks may be triggered by the mainshock aftershock, indicating that the mainshock has a significant triggering effect on the subsequent aftershocks. Based on stochastic finite fault model, we simulated regional peak ground acceleration (PGA), peak ground velocity (PGV) and the intensity, and results could capture basic features associated with the ground motion patterns. Moreover, the simulated results reflect the obvious rupture directivity effect.
\end{abstract}

\section{INTRODUCTION}

According to China Earthquake Networks Center, on August 8, 2017, an earthquake of $M_{\mathrm{L}} 7.0$ struck Jiuzhaigou, Sichuan province, China. This event is another violent earthquake following 2008, Wenchuan $M_{\mathrm{s}} 8.0$ event and 2013, $M_{\mathrm{s}} 7.0$ Lushan event. The U.S. Geological Survey (USGS) assigned a magnitude of $M_{\mathrm{w}} 6.5$ with the epicenter location of $33.20^{\circ} \mathrm{N}$, $103.82^{\circ} \mathrm{E}$, and focal depth of $13.5 \mathrm{~km}$ for this event. As of August 8, Jiuzhaigou earthquake affected more than 180 thousand people, 25 people were killed, 525 people were injured and more than 73671 housing collapsed. Figure 1 shows the epicenter location (blue star), the topographic map and aftershocks (red dots) $M_{\mathrm{L}} \geq 1.0$ of Jiuzhaigou earthquake. This earthquake occurred at the eastern margin of the Qinghai Tibet Plateau, the northeast border of the Bayan karat block. Historical seismicity is quite frequent. The largest event is the 1879 Wudu south M 8.0 earthquake.

There is a general concern about the development of subsequent aftershocks after mainshock. According to the classical aftershock static triggering theory, King et al. (1994) gave a specific method to calculate the static Coulomb stress change ( $\triangle \mathrm{CFS}$ ) after mainshock. The obtained results can be used to explain the distribution of aftershocks. Jiuzhaigou 7.0 earthquake caused building damage and casualties, and triggered geological disasters such as landslides. However, compared with $M_{\mathrm{s}}$ 7.0 Lushan event which has similar magnitudes, damage caused by Jiuzhaigou earthquake is relatively weak. Whether it's calculating the static Coulomb stress change or simulating the strong ground motion, source parameters, especially the fault slip model, should be estimated properly.

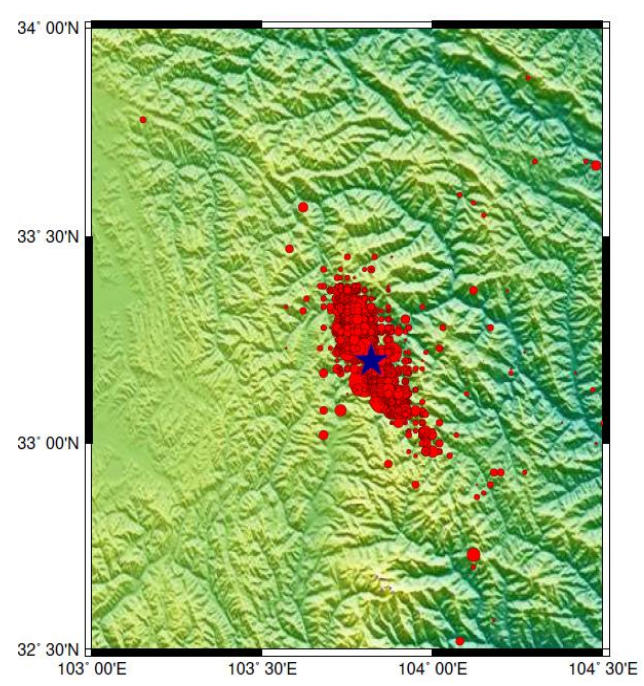

Figure 1. Map of the location of Jiuzhaigou M7.0 earthquake and its aftershocks distribution from the mainshock to October 22, 2017 for $M_{\mathrm{L}} \geq 1.0$. Blue star indicated epicenter location of the mainshock, and red dots indicated aftershock locations.

In this study, base on the Sentinel-1 SAR data, we obtained the coseismic deformation field of Jiuzhaigou M 7.0 earthquake and inverted the coseismic slip distribution on the fault. Based on the inverted slip mode, we calculated the static Coulomb stress change and analyzed the triggering effect of main shock on aftershocks. In addition, based on the stochastic finite fault model (Motazedian and Atkinson, 2005), we simulated the

\footnotetext{
* Corresponding author
} 
strong ground motion and analyzed the possible influence of source parameters on strong ground motion.

\section{INSAR COSEISMIC DEFORMATION AND SLIP MODEL INVERSION}

In the past decades, InSAR (Interferometric Synthetic Aperture Radar) has been widely used to measure surface displacements with unprecedented spatial coverage and resolution. In this paper, we use the Sentinel-1 SAR data to obtain the wide coverage of the coseismic deformation field, and then the inversion code, SDM, developed by Wang et al. (2013) is used to derive the coseismic slip distribution on the fault.

The SAR data from the Sentinel-1 double satellite formation of the ESA was obtained at the first time to derive the precise coseismic surface displacements. The ascending interference pair is 2017/07/30-2017/08/11, and the descending interference pair is 2017/08/06-2017/08/12. In this study, the ISCE software was used to interfere with SAR data. A 30 meter resolution of SRTM-DEM data was used as the external DEM data. The raw radar scenes were processed using the JPL/Caltech ROI_PAC software and the phase was unwrapped using FRAM-SABS software. The scenes and data used in this study are shown in Table 1.

\begin{tabular}{|l|l|l|l|}
\hline Track & $\begin{array}{l}\text { Flight } \\
\text { direction }\end{array}$ & $\begin{array}{l}\text { Perpendicular } \\
\text { baseline }\end{array}$ & Incidence \\
\hline T128 & Ascending & $35 \mathrm{~m}$ & $44^{\circ}$ \\
\hline T62 & Descending & $-92 \mathrm{~m}$ & $42^{\circ}$ \\
\hline
\end{tabular}

Table 1. Interferograms used for the 2017 Jiuzhaigou 7.0 Event

The resulting line-of-sight (LOS) displacement is shown in Figure 2. In order to make the computation feasible and efficient, it's necessary to down-sample the InSAR observations into limited numbers. We employed a Quadtree method (Jónsson et al., 2002) to down-sample data points, and 1630 and 459 points were left for ascending and descending deformation field respectively.

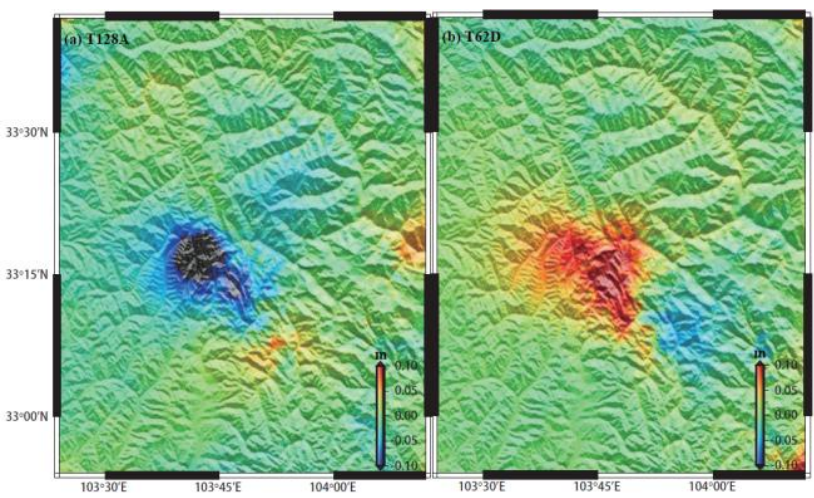

Figure 2. (a) Coseismic deformation of ascending rail for Jiuzhaigou earthquake; (b) Coseismic deformation of descending rail for Jiuzhaigou earthquake.

During the inverting process, the fault geometry is generally guided by the focal mechanism reported by USGS. We assumed planar fault geometry with a strike of $246^{\circ}$ and a dip of $80^{\circ}-90^{\circ}$. The fault dimension is $40 \mathrm{~km}$ along strike and $32 \mathrm{~km}$ in the down dip direction. We discretized the fault plane into $20 \times 16$ patches. Both dip- and strike-slip were allowed for each fault patch, while the rake was set to vary in a range from $-20^{\circ}$ to $20^{\circ}$ in order to be consistent with the focal mechanism. Using a layered crustal structure and InSAR observations collected in this study, the best-fit slip distribution of the mainshock suggests a maximum slip of $0.73 \mathrm{~m}$ occurs at a depth of about $10 \mathrm{~km}$. The total released seismic moment is $8.06 \times 10^{18} \mathrm{~N}$.m, equivalent to an earthquake of $M_{\mathrm{w}} \sim 6.57$. Figure 3 shows the inverted slip model. Similar to other researchers' result, slip on the fault in this study is concentrated above $20 \mathrm{~km}$ depth, especially in the maximum sliding area, the fault is almost pure strike slip, and there is small amount of rupture on the surface. This may be the reason of no apparent fracture zone was found in the field survey. Compared with the results of seismic wave inversion, the inverted slip model in this study also show considerable amount of slip below the depth of $20 \mathrm{~km}$, which released about $1.20 \times 10^{18}$ N.m seismic moment, accounting for $14.89 \%$ of the total seismic moment, equivalents to the scale of $M_{\mathrm{w}} \sim 6.0$ earthquake. Considering that the InSAR data used in this study is taken from the image three or four days after the mainshock, therefore, the deformation field is not only coseismic, but also include postseismic deformation and strong aftershocks signals. This may be the cause of slip at the bottom of the fault.

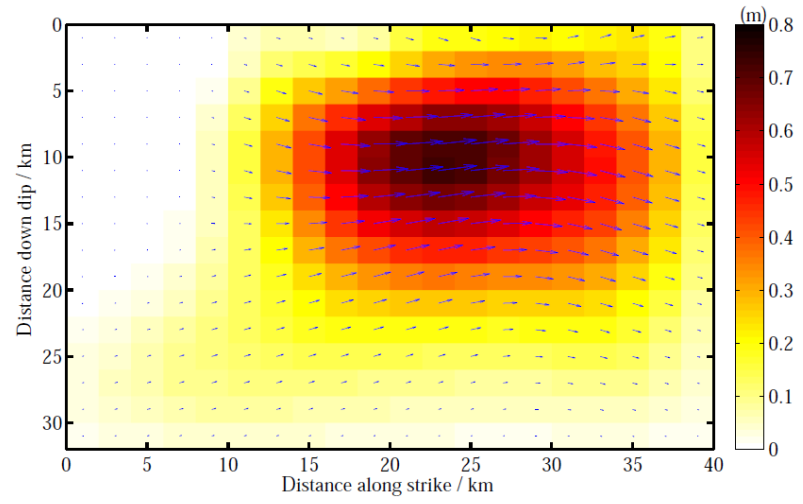

Figure 3. Slip model of Jiuzhaigou 7.0 Earthquake inverted from InSAR data

The static stress drop on the fault plane itself is linked to the dynamics of earthquake rupture and hence also to the associated energy release and seismic radiation (Ripperger and Mai, 2004). Its average value is of particular interest in the study of postseismic stress relaxation and the effect of earthquake rupture on regional stresses and geodynamics (Brown et al., 2015). In this study, we relate slip and stress change to one another by a convolutional integral (Andrews, 1980), expressed as a multiplication in the wavenumber domain, as:

$$
\Delta \sigma\left(k_{x}, k_{y}\right)=K\left(k_{x}, k_{y}\right) \cdot D\left(k_{x}, k_{y}\right),
$$

where $k_{x}$ is the wavenumber along strike and $k_{y}$ is the wavenumber down-dip. $\Delta \sigma\left(k_{x}, k_{y}\right)$ and $D\left(k_{x}, k_{y}\right)$ denotes the twodimensional stress change and slip, respectively, in the wavenumber domain. $K\left(k_{x}, k_{y}\right)$ represents the static stiffness function that for crustal rocks, that is given by Andrews (1980). Figure 4 displays the stress changes calculated with Andrews' method based on our InSAR slip model. The static stress changes in the dip component range from a maximum stress drop of $1.04 \mathrm{MPa}$ to a maximum stress increase of $1.06 \mathrm{MPa}$. While the maximum value of stress drop reaches to $2.24 \mathrm{MPa}$, and stress increase is up to $0.88 \mathrm{MPa}$ in the strike component. The value of average stress drop is derived as the arithmetic mean of the stress drops over the entire rupture zone which is calculated as $1.19 \mathrm{MPa}$, lower than the average level of moderate strike earthquake (Mohammadioun and Serva, 2001). 

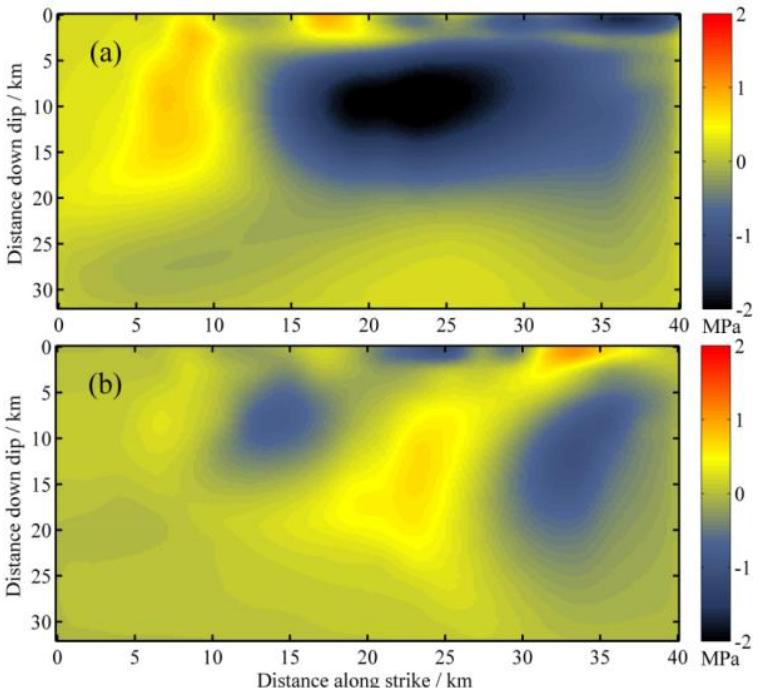

Figure 4. (a) Strike-parallel component of static stress change; (b) Up-dip component of static stress change.

\section{STATIC COULOMB STRESS CHANGE}

Base on the inverted slip model, we calculated the coseismic static Coulomb stress change caused by Jiuzhaigou 7.0 earthquake using Coulomb 3.3 software (Lin and Stein, 2004). During the calculation, the world stress map 2016 (http://dataservices.gfzpotsdam.de/wsm/showshort.php?id=esci doc:1680890) provide the azimuth and plunge of regional stress field. The shear modulus of the crust is set as $3.3 \times 10^{10} \mathrm{~Pa}$, the Poisson's ratio is taken as 0.25 , and the equivalent friction coefficient is set as 0.4 (King et al., 1994).
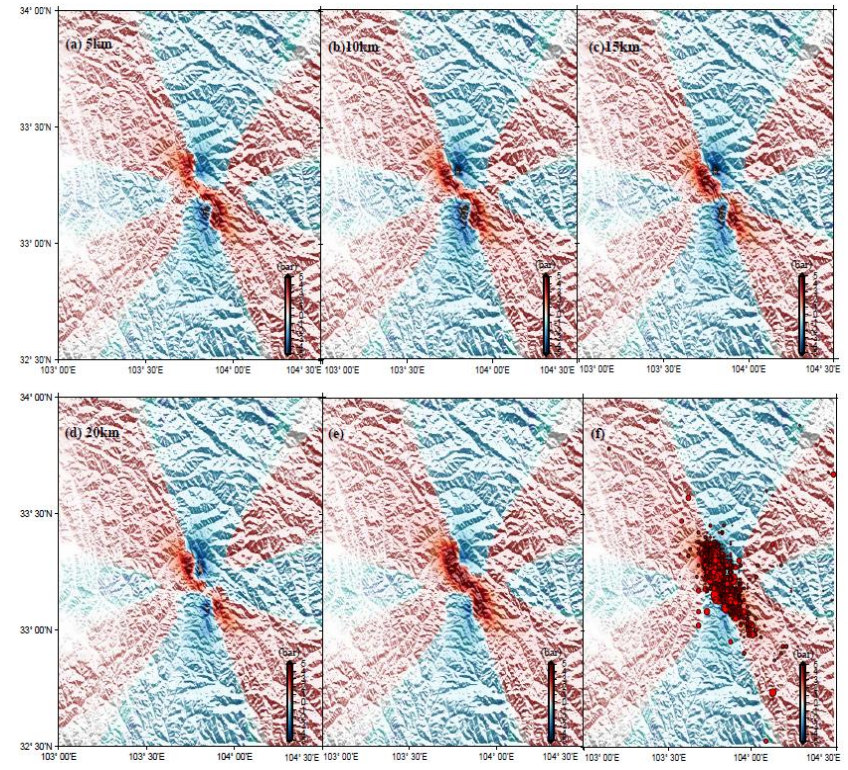

Figure 5. Map views of Coulomb stress change of Jiuzhaigou 7.0 earthquake and aftershocks distribution. (a) Coulomb stress change calculated at $5 \mathrm{~km}$ depth; (b) Coulomb stress change calculated at $10 \mathrm{~km}$ depth; (c) Coulomb stress change calculated at $15 \mathrm{~km}$ depth; (d) Coulomb stress change calculated at $20 \mathrm{~km}$ depth; (e) The maximum calculated Coulomb stress change

between 5 km-20 km depth; (d) Calculated Coulomb stress change with aftershocks distribution.
Figure 5 shows the calculated static Coulomb stress changes at different depths. The calculated depths for Figure 5(a)-(d) are 5 $\mathrm{km}, 10 \mathrm{~km}, 15 \mathrm{~km}$ and $20 \mathrm{~km}$ respectively. Figure 5(e) is the maximum calculated Coulomb stress change between $5 \mathrm{~km}-20$ km depth and Figure 5(f) shows the calculated Coulomb stress change with aftershocks distribution. It's clear that the spatial distribution of aftershocks is striped, and the dominant distribution direction is NW, which is consistent with the area that the static Coulomb stress change increasing. Results indicated that $82.59 \%$ of aftershocks are located in the Coulomb stress increasing area. Research shows that aftershocks could be triggered when $\triangle \mathrm{CFS}>0.01 \mathrm{MPa}$ (King et al., 1994). According to this instruction, $78.42 \%$ of total aftershocks may be triggered by the mainshock, indicating that the mainshock has a significant triggering effect on the subsequent aftershocks for Jiuzhaigou event.

\section{STRONG MOTION SIMULATION}

In this work, we use the common and well known simulation methods: the stochastic finite-fault simulation code (EXSIM, Motazedian and Atkinson, 2005; Boore, 2009). The stochastic finite-fault model is an extension of the point-source stochastic method (Boore, 1983, 2003) which includes the rupture propagation along an extended fault (Ameri et al., 2011). In EXSIM, the fault is divided into $N$ subfaults; each of them is considered as a point source, emitting an $\omega$-square spectrum. Ground motions produced by subfaults are summed in the time domain with a proper time delay, to obtain the ground motions from the entire fault. EXSIM has several significant advantages over previous stochastic finite-fault models, including independence of results from subfaults size, conservation of radiated energy, and the ability to have only a portion of the fault active at anytime during the rupture (simulating selfhealing behaviour (Heaton, 1990)). It has been widely used in strong ground motions predication and simulation (Atkinson and Boore, 2006).The finite-fault model geometry and slip distribution are directly adopted from InSAR inversion results. The associated Q-model is given by Qiao et al., (2006), which is $334.4 f^{0.581}$, and the geometrical spreading and duration model are adopted from Motazedian and Atkinson's predictions of ground motion in North America. The detail input parameters used in EXSIM are shown in Table 2.

\begin{tabular}{|c|c|c|}
\hline Parameter & Value & Parameter source \\
\hline Focal mechanism & $\begin{array}{l}\text { strike: } 246^{\circ} \\
\text { dip: } 85^{\circ}\end{array}$ & USGS \\
\hline $\begin{array}{l}\text { Moment } \\
\text { magnitude }\end{array}$ & 6.57 & InSAR inversion \\
\hline Stress drop & $1.19 \mathrm{MPa}$ & InSAR inversion \\
\hline Fault dimension & $40 \mathrm{~km} \times 32 \mathrm{~km}$ & InSAR inversion \\
\hline Rupture velocity & $0.8 \beta$ & $\begin{array}{l}\text { Atkinson and Boore } \\
\text { (2006) }\end{array}$ \\
\hline $\begin{array}{l}\text { Pulsing } \\
\text { percentage }\end{array}$ & $50 \%$ & $\begin{array}{l}\text { Atkinson and Boore } \\
\text { (2006) }\end{array}$ \\
\hline $\begin{array}{l}\text { Shear-wave } \\
\text { velocity }\end{array}$ & $3.7 \mathrm{~km} / \mathrm{s}$ & \\
\hline Quality factor & $334.4 f^{0.581}$ & Qiao et al., (2006) \\
\hline
\end{tabular}

Table. 2 Simulating strong motion parameters for Jiuzhaigou 7.0 earthquake by Finite Stochastic Model 
The simulation is done on a rectangular grid of sites $\left(32^{\circ} \mathrm{N}-\right.$ $34.5^{\circ} \mathrm{N}, 102.5^{\circ} \mathrm{E}-105^{\circ} \mathrm{E}$ ), with a $0.05^{\circ}$ spacing. For each site, the code runs for 10 times, and we take the average value of these simulations as the final value of PGA and PGV. Figure 6 displays the simulated ground-motions characterized by Lg(PGA), Lg(PGV) and MMI.

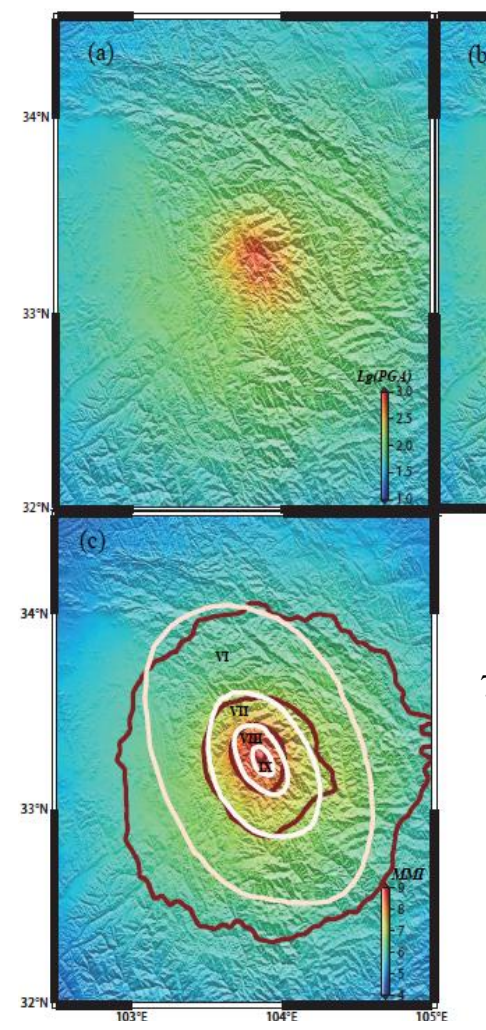

It's clear that the simulated ground motions are able to match several salient features of the ground shaking distributions, such that the correlation between synthetic meizoseismal areas is consistent with the field observation, and the distribution range that other MMI value corresponds is also approximately match. Moreover, the simulated results reflect the obvious rupture directivity effect and are in good agreement with observed result

\section{CONCLUSION}

In this study, base on Sentinel-1 double satellite formation of the ESA, we obtain the coseismic deformation field of Jiuzhaigou 7.0 earthquake. Adopting the inversion code, SDM, we derive the coseismic slip distribution on the fault. InSAR inversion shows that Jiuzhaigou M7.0 event is dominated by strike slip, and the maximum slip on fault is $0.73 \mathrm{~m}$, the average slip comes to $0.21 \mathrm{~m}$, and the total released seismic moment is $8.06 \times 10^{18} \mathrm{~N} \cdot \mathrm{m}$, equivalent to an earthquake of $M_{\mathrm{w}} \sim 6.57$. Then, the static stress and slip heterogeneity analysis are conducted, which show that both the average stress drop and corner wavenumber are at low level, and this is consistent with previous findings. The static stress changes in the dip component range from a maximum stress drop of $1.04 \mathrm{MPa}$ to a maximum stress increase of $1.06 \mathrm{MPa}$. While the maximum value of stress drop reaches to $2.24 \mathrm{MPa}$, and stress increase is up to $0.88 \mathrm{MPa}$ in the strike component. The average stress drop value for the entire rupture zone is $1.19 \mathrm{MPa}$, which is lower than the average level of moderate strike earthquake. The coseismic Coulomb stress changes are calculated base on the inverted slip model, which revealed that $82.59 \%$ of aftershocks are located in the Coulomb stress increasing area, $78.42 \%$ of total aftershocks may be triggered by the mainshock aftershock, indicating that the mainshock has a significant triggering effect on the subsequent aftershocks. Based on stochastic finite fault model, we simulated regional peak ground acceleration (PGA), peak ground velocity (PGV) and the intensity, and results could capture basic features associated with the ground motion patterns. Moreover, the simulated results reflect the obvious rupture directivity effect and are in good agreement with the station records and attenuation curve.

\section{ACKNOWLEDGEMENTS}

This work was supported by a research grant from the Institute of Crustal Dynamics, China Earthquake Administration [grant number ZDJ2017-29].

\section{REFERENCES}

Ameri, G., Emolo, A., Pacor, F., Gallovic, F., 2011. Ground motion simulation for the $1980 M 6.9$ Irpinia earthquake (Southern Italy) and scenario events. Bulletin of the Seismological Society of America, 101(3),pp.1136-1151.

Andrews, D. J., 1980. A stochastic fault model: 1. Static case. Journal of Geophysical Research, 85,pp. 3867- 3877.

Atkinson, G. M., Boore, D. M., 2006. Earthquake groundmotion prediction equations for eastern North America. Bulletin of the Seismological Society of America, 96,pp. 2181-2205.

Boore, D. M., 1983. Stochastic simulation of high-frequency ground motion based on seismological models of the radiated spectra. Bulletin of the Seismological Society of America,73,pp.1865-1894.

Boore, D. M., 2003. Simulation of ground motion using the stochastic method. Pure and Applied Geophysics,160,pp.635676 .

Boore, D. M., 2009. Comparing stochastic point-source and finite-source ground-motion simulations: SMSIM and EXSIM. Bulletin of the Seismological Society of America, 99,pp.32023216.

Brown, L., Wang, K.L., Sun, T.H., 2015. Static stress drop in the $M_{\mathrm{w}} 9$ Tohoku-oki earthquake: Heterogeneous distribution and low average value. Geophysical Research Letters, 42(24), pp.10595-10600.

Heaton, T. H., 1990. Evidence for and implications of self healing pulses of slip in earthquake rupture. Physics of the Earth and Planetary Interiors, 64,pp.1-20.

Jónsson, S., Zebker, H., Segall, P., Amelung, F., 2002. Fault Slip Distribution of the 1999 Mw7.1 Hector Mine, California Earthquake, Estimated from Satellite Radar and GPS Measurements. Bulletin of the Seismological Society of America, 92, pp.1377-1389.

King, G. C. P., Stein, R. S., Lin. J., 1994. Static stress changes and the triggering of earthquakes, Bulletin of the Seismological Society of America, 84,pp. 935-953. 
Lin, J., Stein, R. S., 2004. Stress triggering in thrust and subduction earthquakes and stress interaction between the southern San Andreas and nearby thrust and strike-slip faults. Journal of Geophysical Research, 109,pp.B02303.

Mohammadioun, B., Serva, L., 2001. Stress Drop, Slip Type, Earthquake Magnitude, and Seismic Hazard. Bulletin of the Seismological Society of America, 91(4),pp.694-707.

Motazedian, D., Atkinson, G.M., 2005. Stochastic finite-fault modeling based on a dynamic corner frequency. Bulletin of the Seismological Society of America, 95, pp.995-1010.

Qiao, H. Z., Zhang, Y. J., Cheng, W. Z., Liu, J., 2006. The inversion of the inelastic coefficient of the medium in NorthWest of Sichuan Province. Seismological and Geomagnetic Observation and Research, 27,pp.1-7.

Ripperger, J., Mai, P. M., 2004. Fast computation of static stress changes on 2D faults from final slip distributions. Geophysical Research Letters, 31,pp. L18610.

Wang, R., Diao, F., Hoechner, A., 2013. SDM-a geodetic inversion code incorporating with layered crust structure and curved fault geometry, in Proceedings of the EGU General Assembly 2013, 15, EGU2013-2411-1. 